\title{
AVALIAÇÃO DO ÍNDICE DE ESTADO TRÓFICO DO PARQUE AQUÍCOLA SUCUPIRA, RESERVATÓRIO DO LAJEADO, PALMAS (TO)
}

\author{
Clauber Rosanova* \\ Emílio Sousa Pinho** \\ Rubens Tomio Honda*** \\ Flavia Tavares Matos***** \\ Vailton Alves Farias****** \\ Alberto Akama******
}

RESUMO: A aquicultura é a atividade que mais cresce dentre os setores de produção de alimentos, porém, sua prática pode causar impactos ao ambiente de cultivo. $\mathrm{O}$ objetivo do trabalho foi avaliar o grau de trofia do Parque Aquícola Sucupira, área de cultivo de peixes em tanques-rede localizada no reservatório do Lajeado em Palmas, no Tocantins, utilizando o Índice de Estado Trófico (IET). O monitoramento foi realizado no período de janeiro a abril de 2017, envolvendo a coleta de amostras para análises dos parâmetros de fósforo total e clorofila-a. Paralelamente, houve realização de coleta de dados de temperatura, turbidez, oxigênio dissolvido, condutividade, $\mathrm{pH}$ e sólidos totais dissolvidos in loco. Os resultados do cálculo do Índice de Estado Trófico (IET) mostraram que a área em estudo durante os meses de janeiro a abril apresentou predominância de grau supereutrófico. Tudo indica que o estado trófico do lago nas proximidades da área aquícola sofre forte influência do período de chuva, porém, como os estudos não foram realizados no período de estiagem, não há como diferenciar os efeitos da chuva e da atividade piscícola no ambiente em estudo. Desta forma, novos estudos são necessários para entender os efeitos da atividade aquícola nos parâmetros de qualidade de água a médio e longo prazo, por meio da execução de planos de monitoramento limnológico.

PALAVRAS-CHAVE: Aquicultura; Eutrofização; Impacto ambiental; Poluição; Tanque rede.

\footnotetext{
${ }^{*}$ Doutorando do programa em Ciências do Ambiente, Unidade Federal do Tocantins - UFT, Palmas, Brasil. E-mail: clauber@ifto.edu.br

** Graduando de Engenharia Ambiental e Sanitária da Faculdade Católica do Tocantins, Brasil.

*** Doutorado em Biologia (Ecologia) pelo Instituto Nacional de Pesquisas da Amazônia - INPA, Manaus, Brasil.

${ }^{* * * *}$ Doutora em Engenharia Ambiental pela Universidade Federal de Santa Catarina - UFSC, Florianópolis, Brasil.

${ }^{* * * * *}$ Doutorando em Ciências do Ambiente pela Universidade Federal do Tocantins - UFT, Palmas, Brasil.

****** Doutorado em Ciências Biológicas (Zoologia) pela Universidade de São Paulo - USP, Brasil.
} 


\section{EVALUATION OF THE TROPHIC STATE INDEX OF THE SUCUPIRA AQUICULTURE PARK, LAJEADO RESERVOIR, IN PALMAS, BRAZIL}

ABSTRACT: Aquaculture is a growing activity within the food producing segments, however, it may affect the environment. Current analysis studied the trophic state of the Sucupira Aquaculture Park, an area for fish cultivation in net cages locateds in Lajeado Reservoir - Palmas (TO) - Brazil, applying the Trophic State Index (TSI)). Monitoring was undertaken between January and April of 2017 and comprised sampling for the analysis of total phosphorus and chlorophyll-a. Water quality data as temperature, turbidity, dissolved oxygen, conductivity, $\mathrm{pH}$ and dissolved total solids were obtained in loco. Considering the TSI resultsbetween January and April, the area was predominantly supereutrophic. It can be observed that the lake's trophic statewithin $\mathrm{t}$ aquaculture area is highly influenced by the rainy period. Since studies were not undertaken during the dry period, the differences between rain effects and fish farming activities were not possible to be detected. Further studies are required to understand the effects of aquaculture activities in the environment in a short and medium term by limnological monitoring.

KEY WORDS: Aquaculture; Eutrofication; Environmental impact; Pollution; Net tank.

\section{INTRODUÇÃO}

A aquicultura é a atividade que mais cresce dentre os setores de produção de alimentos. $\mathrm{O}$ crescimento na oferta mundial de peixe para consumo humano ultrapassou o crescimento da população nas últimas cinco décadas, aumentando a uma taxa anual média de 3,2\% no período de 1961-2013, o dobro do crescimento da população humana, o que resulta no aumento da média de disponibilidade per capita (FOOD AND AGRICULTURE ORGANIZATION, 2016).

Sendo assim, a aquicultura atualmente enfrenta desafio para encontrar soluções de produção sem grandes agressões ao meio ambiente, buscando da melhor forma possível o conceito da sustentabilidade. Deve-se entender que a preservação ambiental é parte do processo produtivo, uma vez que é necessária também água de boa qualidade para saúde do animal (VALENTI; PEREIRA; BORGHETTI, 2000).

A grande disponibilidade de áreas cobertas de água em reservatórios de 
usinas hidrelétricas faz do Estado do Tocantins um grande potencial para produção de pescado em tanques-rede. A implantação das áreas aquícolas no reservatório do Lajeado, que ocorreu no ano de 2015, é resultado de ações do Ministério de Pesca e Aquicultura, juntamente com Agência Nacional de Águas (ANA), Marinha do Brasil e o Instituto Brasileiro do Meio Ambiente e dos Recursos Naturais Renováveis (IBAMA). No contexto geral da produção de peixes de modo racional e responsável são necessárias técnicas de monitoramento ambiental para o acompanhamento da qualidade da água no decorrer da linha de cultivo. O monitoramento ambiental de sistemas aquáticos é uma ótima ferramenta para subsidiar as tomadas de decisões e previsão de impactos (ALCÂNTARA et al., 2013), e necessita ser fortalecida e implementada em políticas públicas que desenvolvem os sistemas de criação de peixes.

A avaliação do grau de eutrofização em lagos e reservatórios é feita tradicionalmente em diversos países. A preocupação com a vida aquática e com os inúmeros impactos causados pelos usos inadequados em reservatórios proporcionou vários estudos limnológicos, motivados principalmente por causa dos usos múltiplos deste recurso, por exemplo, uso para abastecimento humano, receptor de águas residuárias, produção de peixes e irrigação. $\mathrm{O}$ aumento de nutrientes em muitos corpos de água lênticos são algumas das razões para a priorização dos estudos sobre eutrofização nesses ambientes, em relação aos ambientes lóticos que possuem dinâmica de depuração e ciclagem de nutriente muito diferente (LAMPARELLI, 2004).

$\mathrm{O}$ aumento de nutrientes a base de fósforo e nitrogênio em ecossistemas aquáticos é considerado processo dinâmico de eutrofização com grandes prejuízos ao ambiente natural (ESTEVES, 1998). A eutrofização artificial causa grandes perdas à qualidade da água e é a partir de ações antrópicas, como a irrigação e a descarga de efluente doméstico. Geralmente, esta eutrofização leva ao aumento de algas, muitas delas produtoras de citotoxinas (BARBOSA et al., 2006). De acordo com Smith e Schindler (2009); Tundisi e Matsumura-Tundisi (2008); Esteves (1998), estes autores dizem que o processo de eutrofização leva à alteração nas condições de qualidade de água, sabor, odor, turbidez, redução de oxigênio dissolvido, alteração da biodiversidade aquática, além do crescimento excessivo de plantas aquáticas.

A eutrofização pode ser considerada como uma reação dinâmica no meio, na qual a principal característica é a quebra da estabilidade do ecossistema. Quanto 
mais nutrientes no ecossistema do que o suportável para consumo e decomposição, maior a instabilidade na autodepuração com o rompimento do estado de equilíbrio devido à eutrofização, o ecossistema assume outra dinâmica de estrutura das relações biológicas em consequência das alterações das características físicas e químicas da água (ESTEVES, 1998).

O trabalho de Vollenweider (1968) é considerado marco inicial de estudos de eutrofização em ambientes aquáticos. Depois disso, muitos pesquisadores começaram a atuar em diversas partes no mundo em ambientes lênticos e lóticos. Atualmente, existe uma variação de modelos de classificação de ambientes. Por exemplo, Wetzel (1993) utiliza o parâmento de clorofila-a como indicador de ambientes eutrofizados (> $\left.>\mu \mathrm{gL}^{-1}\right)$. Já Carlson (1977), Toledo et al. (1984), Salas e Martino (1991), OECD (ORGANIZATION FOR ECONOMIC COOPERATION AND DEVELOPMENT, 1992) e Lamparelli (2004) utilizam o comportamento do fósforo para análise de eutrofização desses ambientes.

$\mathrm{Na}$ tentativa de se monitorar ambientes aquáticos, torna-se importante o conhecimento das condições de trofia destes ambientes, a partir de limites calculados por indicadores correlacionados ao favorecimento da eutrofização, por exemplo, ao cálculo do Índice de Estado Trófico (IET) que tem por finalidade classificar os corpos d'água em diferentes graus de trofia, ou seja, avalia a qualidade da água quanto ao enriquecimento por nutrientes e seu efeito relacionado ao crescimento excessivo das algas (COMPANHIA AMBIENTAL DO ESTADO DE SÃO PAULO, 2009a).

Lamparelli (2004) afirma que nos cálculos para classificação de trofia em reservatórios são necessários os parâmetros de clorofila-a e fósforo total. O pigmento de clorofila é encontrado em plantas e alguns tipos de algas de águas continentais, a alta concentração desse parâmetro é um indicador de fitoplâncton no ambiente.

O estado trófico de um corpo de água pode ser classificado como oligotrófico, mesotrófico, eutrófico, supereutrófico e hipereutrófico, de acordo com a classificação do estado trófico dos cursos d'água continentais utilizado pela CETESB (COMPANHIA AMBIENTAL DO ESTADO DE SÃO PAULO, 2009a) para identificar o grau de poluição ou a condição ambiental da região.

Mallasen et al. (2012) avaliaram a condição da qualidade da água em um sistema de piscicultura em tanques-rede no Reservatório de Ilha Solteira, São Paulo, e concluíram que a produção de peixes na região provoca baixo impacto 
no ecossistema aquático. O reservatório demonstrou ser eficiente na capacidade de assimilação da carga de nutrientes proveniente de produção de pescado.

Outro estudo a respeito desse tema foi realizado no reservatório de Tucuruí $(\mathrm{PA})$, que simulou a produção de peixe em gaiolas e avaliou os impactos dessa atividade na qualidade da água. Os resultados desse trabalho indicaram aumento de $30 \%$ da carga de fósforo no local do cultivo, entre 2007 e 2011, sugerindo ambiente hipertrófico (DEUS et al., 2013). Nesse contexto, o objetivo desse estudo foi avaliar o grau de trofia do ambiente em uma atividade aquícola de sistema de produção em tanques-rede, localizado no reservatório de Lajeado, Palmas (TO), mais precisamente no Parque Aquícola Sucupira, utilizando-se como parâmetro o Índice de Estado Trófico de Lamparelli (2004).

\section{MATERIAL E MÉTODOS}

\section{1 ÁREA DE ESTUDO}

A região de estudo delimitada neste trabalho foi a área de influência de produção de pescado em tanques-rede do Parque Aquícola Sucupira, localizada no reservatório do Lajeado a $15 \mathrm{~km}$ da cidade de Palmas (TO), com coordenadas geográficas latitude -10,0857 e longitude -48,3668 em WGS-84, conforme o Quadro 1 e a Figura 1. O reservatório de Lajeado ocupa área de $630 \mathrm{Km}^{2}$ de lâmina de água, representando $0,23 \%$ da área do Estado do Tocantins, tendo sido construído basicamente para geração energética em 2001, com uma produção aproximada de 902,5 MW por dia. Além disso, há outros usos, como usos para abastecimento, irrigação, aquicultura, navegação, lazer entre outros. 
Quadro 1. Coordenadas geográficas dos pontos de amostragens, Reservatório de Lajeado, Palmas, Tocantins, Brasil

\begin{tabular}{|c|c|c|}
\hline Ponto & Longitude & Latitude \\
\hline A1 & $-10,086566$ & $-48,373270$ \\
\hline A2 & $-10,086566$ & $-48,371020$ \\
\hline A3 & $-10,086566$ & $-48,368770$ \\
\hline A4 & $-10,088816$ & $-48,373270$ \\
\hline A5 & $-10,088816$ & $-48,371020$ \\
\hline A6 & $-10,088816$ & $-48,368770$ \\
\hline A7 & $-10,091066$ & -48373270 \\
\hline A8 & $-10,091066$ & $-48,371020$ \\
\hline A9 & $-10,091066$ & $-48,368770$ \\
\hline A10 & $-10,094148$ & $-48,372102$ \\
\hline
\end{tabular}

Pontos de Coleta - Reservatório de Lajeado, Palmas, Tocantins, Brasil.

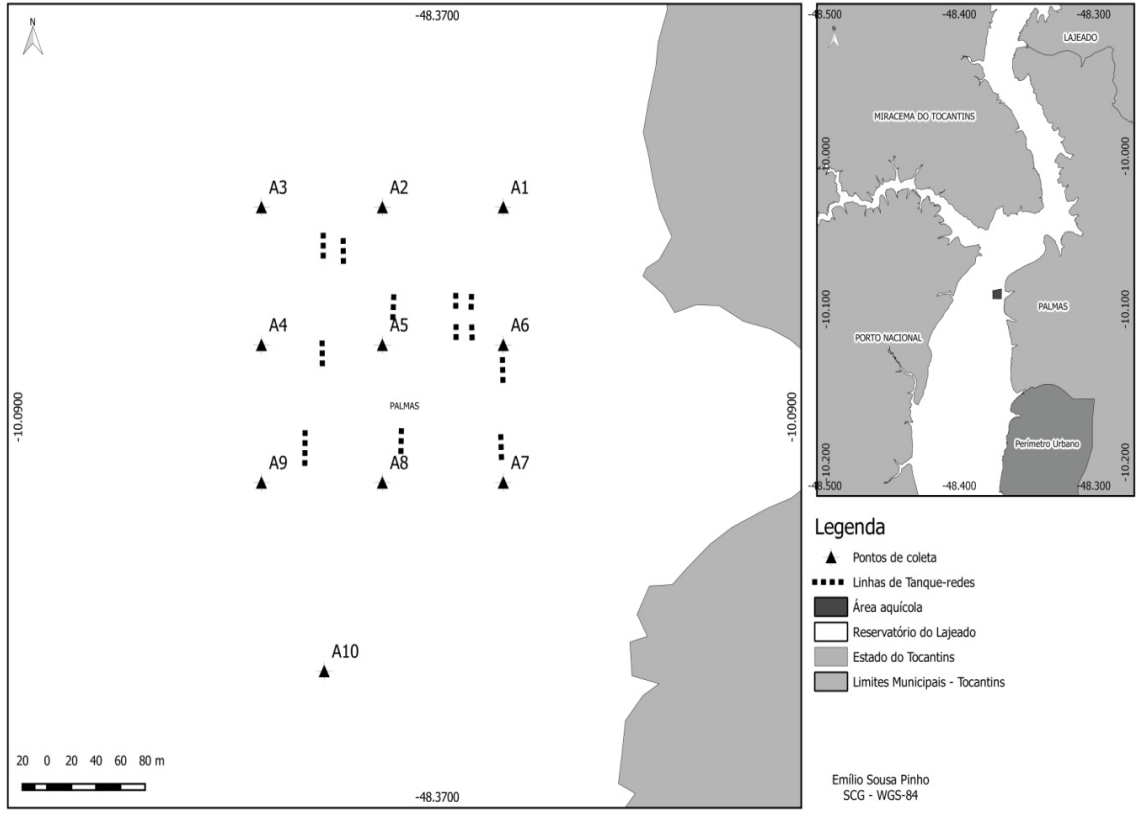

Figura 1. Pontos de coleta (A1 a A10) com as coordenadas em WGS-84; monitoramento da área aquícola, reservatório de Lajeado, Palmas (TO) 


\subsection{COLETA DE DADOS}

As coletas de amostras de água foram realizadas em 9 pontos equidistantes, abrangendo toda área de produção de pescado em tanques-rede, sendo 1 ponto de coleta localizado fora da área de produção como forma de controle (A10). Foram feitas 4 campanhas entre janeiro-2017 e abril-2017, uma a cada mês, no intuito de se determinar as concentrações de fósforo total $\left(\mu \mathrm{gL}^{-1}\right)$ e clorofila-a $\left(\mu \mathrm{gL}^{-1}\right)$, para os cálculos dos Índice de Estado Trófico segundo Lamparelli (2004).

A água foi coletada na lâmina superficial $(30 \mathrm{~cm})$, com auxílio da garrafa de Van Dorn, armazenada em frascos de polietileno de $1 \mathrm{~L}$ e mantidas refrigeradas a $4{ }^{\circ} \mathrm{C}$ e protegidas da luz. Posteriormente, as amostras foram transportadas para o laboratório de Saneamento Ambiental, da Faculdade Católica do Tocantins, para análise (fósforo total e clorofila-a). Parâmetros como temperatura $\left({ }^{\circ} \mathrm{C}\right), \mathrm{pH}$, condutividade $\left(\mathrm{mS} \mathrm{cm}^{-1}\right)$, oxigênio dissolvido $\left(\mathrm{mgL}^{-1}\right)$, sólidos totais $\left(\mathrm{mgL}^{-1}\right)$ e turbidez (NTU) foram analisados in loco mediante o uso de medidor multiparâmetros Horiba U-52G.

\subsection{ANÁLISES DE QUALIDADE DE ÁGUA}

\subsubsection{Determinação da Concentração de Clorofila-a}

A determinação de clorofila-a foi obtida por filtração de $0,5 \mathrm{~L}$ de amostra em membranas de fibra de vidro de $0,45 \mu \mathrm{m}$. A extração das clorofilas foi feita mediante choque térmico com acetona a $90 \%$ e a maceração de cada amostra. Posteriormente, foram centrifugadas a $4000 \mathrm{rpm}$ por 10 minutos e armazenadas em ambiente refrigerado a $4{ }^{\circ} \mathrm{C}$ por 24 horas para posterior análise. A leitura do sobrenadante foi feita com o auxílio de espectrofotômetro em comprimento de onda $664 \mathrm{~nm}, 665 \mathrm{~nm}$ e $750 \mathrm{~nm}$ de acordo com Standard Methods (1998). Os valores das concentrações de clorofila-a foram obtidos por meio da seguinte equação 1 :

$$
C l a\left(\frac{m g}{m^{3}}\right)=\frac{26,7 \times\left[644_{b}-665_{a}\right] \times V 1}{V 2 \times L}
$$


Onde:

664: subtração da absorbância obtida em $\lambda=664 m$ e $\lambda=750 m$

665: subtração da absorbância obtida em $\lambda=665 \boldsymbol{m}$ e $\lambda=750 \boldsymbol{m}$ (densidade óptica após a acidificação)

V1: volume do extrato de acetona $(\mathrm{mL})$

V2: volume filtrado da amostra (Litros)

L: Caminho ótico da cubeta

\subsubsection{Determinação da Concentração de Fósforo Total}

A quantificação de Fósforo total foi feita por meio de dois métodos: primeiro, digestão alcalina utilizando $0,210 \mathrm{mgL}^{-1}$ de Persulfato de Potássio $0,210 \mathrm{mgL}^{-1} \mathrm{em}$ autoclave a $125^{\circ} \mathrm{C}$ por 25 minutos para determinação de todas as formas de fósforos presentes. Posteriormente, a quantificação do fósforo total a partir do método do ácido ascórbico com concentração $17,6 \mathrm{gL}^{-1}$. As leituras das amostras foram feitas em espectrofotômetro a um comprimento de onda $880 \mathrm{~nm}$. A determinação da concentração de Fósforo total foi realizada por meio de curva de calibração, obtida pela correlação de concentrações padrões e os resultados de leituras, no qual o resultado da equação da reta terá uma soma dos quadrados o mais próximo de $\mathrm{R}^{2}=1$, obtida na curva de calibração para fósforo total (MURPHY; RILEY, 1962; AMERICAN PUBLIC HEALTH ASSOCIATION, 1998).

\subsection{3 Índice de Estado Trófico (IET)}

O IET foi calculado com base na média aritmética da concentração das variáveis, clorofila-a e fósforo total, analisadas nos 10 pontos amostrais.

Conforme Alves et al. (2012), o Índice do Estado Trófico (IET) é composto por dois outros Índices: Índice de Estado Trófico para o Fósforo e o Índice de Estado Trófico para a clorofila-a, usados por Lamparelli (2004), sendo estabelecidos para ambientes idênticos.

Para a determinação do IET, conforme Lamparelli (2004), utilizam-se as seguintes equações: 


$$
\begin{aligned}
& \operatorname{IET}_{L}(\mathrm{Cla})=10 \times\left(6-\left(\frac{0,92-0,34(\ln (\mathrm{Cla}))}{\ln 2}\right)\right) \\
& \operatorname{IET}_{L}(P T)=10 \times\left(6-\left(\frac{1,77-0,42(\ln (P T))}{\ln 2}\right)\right) \\
& \operatorname{IET}_{L}=\frac{\operatorname{IET}(P T)+\operatorname{IET}(\mathrm{Cla})}{2}
\end{aligned}
$$

Onde:

IET: Índice de Estado Trófico por Lamparelli (2004)

PT: concentração de fósforo total medida na superfície da água, em $\mu$ g.L $\mathrm{L}^{-1}$

CL: concentração de clorofila total medida na superfície da água, em $\mu \mathrm{g} . \mathrm{L}^{-1}$ Ln: logaritmo

Os valores decimais nas fórmulas são constantes delineadas a partir de experimentos de Lamparelli (2004), a partir de correlações logarítmicas.

\section{RESULTADOS E DISCUSSÃO}

Localizado em uma região de clima tropical, o reservatório do Lajeado está sujeito a mudanças em função do regime pluviométrico. Desta forma, a região do reservatório define-se em duas fases climáticas bem distintas: entres os meses de outubro a março há o regime de chuvas e entres os meses de maio a setembro há restrições de chuvas, de acordo com os dados climatológicos apresentados pelo INMET (Instituto Nacional de Meteorologia), conforme a Gráfico 1. 


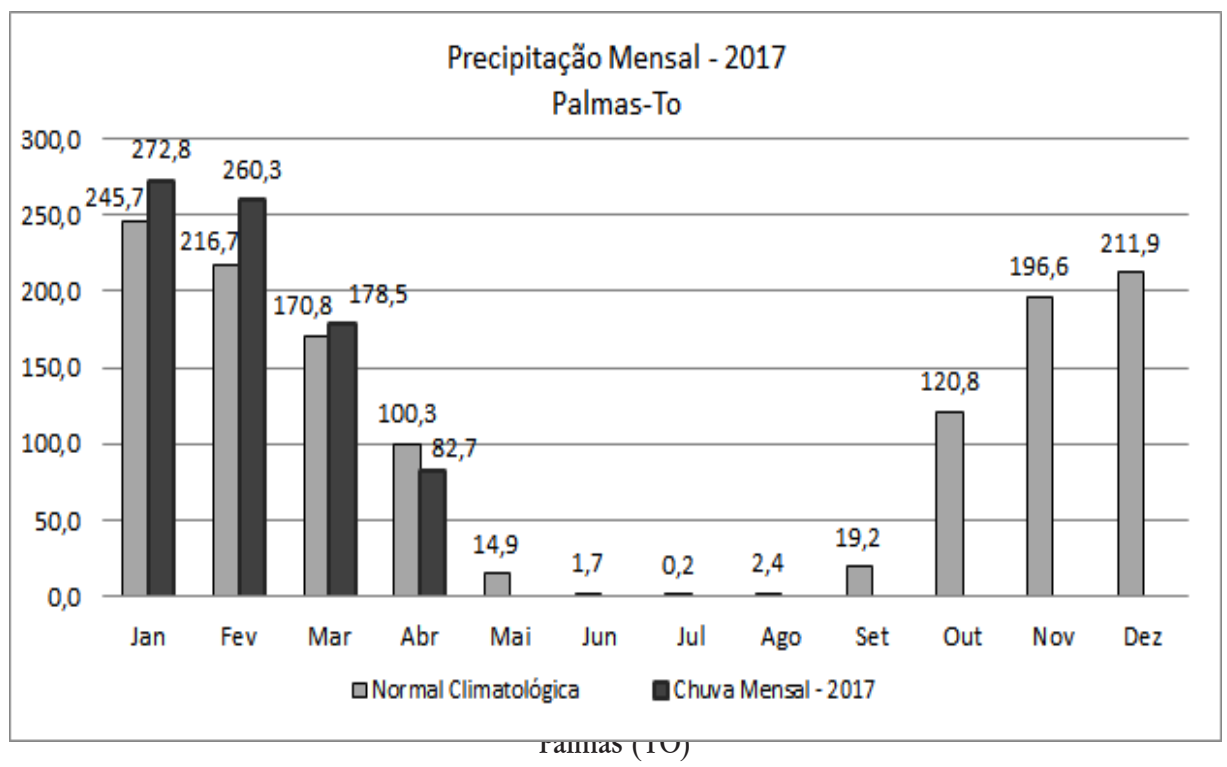

Os gráficos representados na Figura 3 apresentam os resultados dos parâmetros Temperatura $\left({ }^{\circ} \mathrm{C}\right), \mathrm{pH}$, Condutividade $(\mathrm{mScm})$, Turbidez (NTU), Oxigênio Dissolvido $\left(\mathrm{mgL}^{-1}\right)$ e Sólidos Totais Dissolvidos $\left(\mathrm{gL}^{-1}\right)$, durante os meses de janeiro e abril de 2017.

Os parâmetros Temperatura, pH, Condutividade, Turbidez, Oxigênio Dissolvido e Sólidos Totais Dissolvidos apresentam valores médios de $30,46 \pm 0,321{ }^{\circ} \mathrm{C}$, $7,51 \pm 0,163,0,0645 \pm 0,0085 \mathrm{mScm}, 5,00 \pm 0,555 \mathrm{NTU}, 5,315 \pm 0,501 \mathrm{mgL}^{-1}$, e $0,0438 \pm 0,006 \mathrm{gL}^{-1}$, respectivamente, entre os meses de janeiro e abril, conforme representação da Figura 2. A partir desses parâmetros, pode-se afirmar que não houve mudanças significativas durante o monitoramento que pudessem representar alguma alteração da condição do meio aquático. 


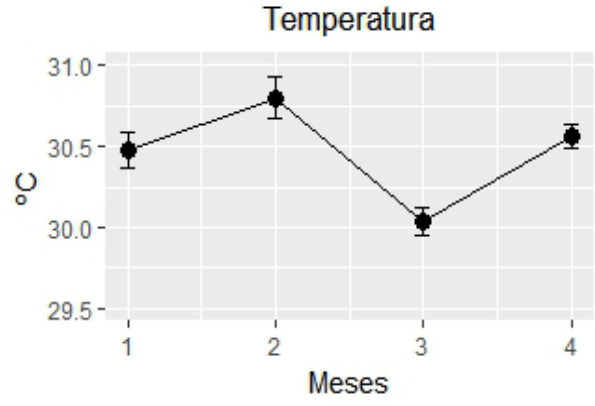

Condutividade
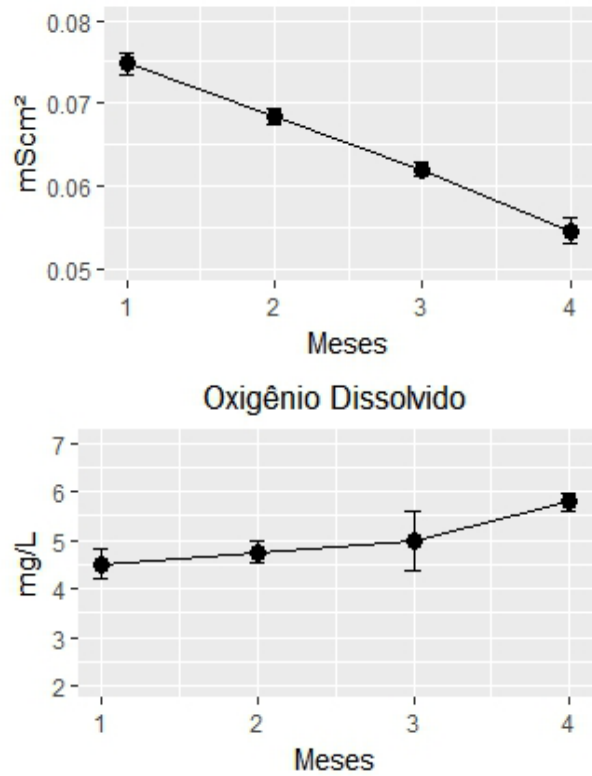

$\mathrm{pH}$

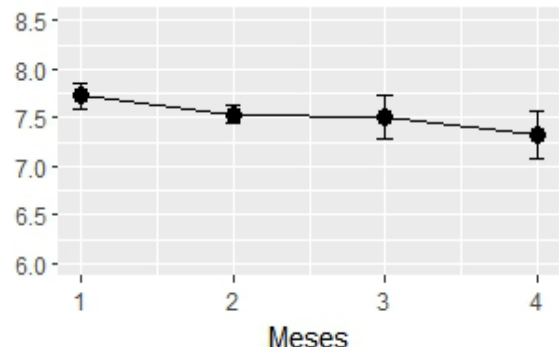

Turbidez

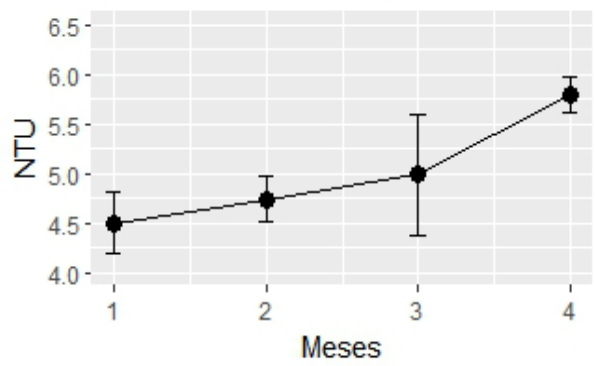

Sólidos Totais Dissolvidos

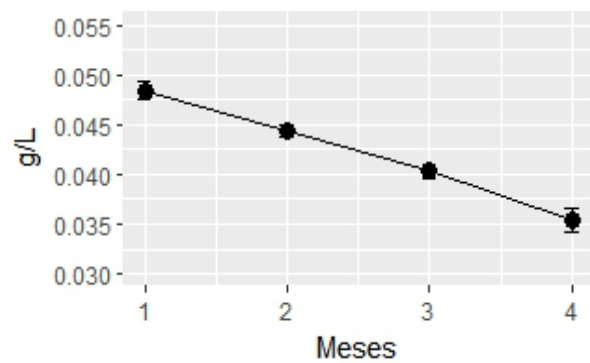

Figura 2. Resultados dos parâmetros de Temperatura, Turbidez, Oxigênio Dissolvido, pH, Condutividade e Sólidos Totais Dissolvidos, $(\mathrm{n}=10)$, obtidos no Parque Aquícola Sucupira - Reservatório de Lajeado

A temperatura da água é fator controlador das atividades metabólicas dos organismos aquáticos que não suportam variações bruscas dessa variável (PADUA, 1996). No período estudado, a temperatura média da água foi de $30,46 \pm 0,321^{\circ} \mathrm{C}$, o que favoreceu o desenvolvimento e desempenho de peixes tropicais via aceleração do metabolismo com consequente aumento da ingestão de alimentos (PEZZATO et 
al., 2004). De acordo com Kubitza (2003), temperaturas da água entre $26^{\circ} \mathrm{C}$ e $30^{\circ} \mathrm{C}$ correspondem a valores ótimos para o cultivo de peixes. Segundo Marques (2006) no reservatório da Usina Hidrelétrica do Lajeado ocorrem variações de temperaturas entre $25^{\circ} \mathrm{C}$ e $31,7^{\circ} \mathrm{C}$.

A condutividade elétrica na área de produção de pescado apresentou valores médios de $0,0545 \pm 2,403 \mathrm{mS} / \mathrm{cm}$, resultados semelhantes aos observados por Peixoto (2007) em estudos na UHE Lajeado. A Resolução CONAMA 357/2005 (BRASIL, 2005) não determina limites de tolerância específicos para cada parâmetro, porém, a CETESB (COMPANHIA AMBIENTAL DO ESTADO DE SÃO PAULO, 2009b) aponta que valores para condutividade elétrica acima de $0,100 \mathrm{mS} / \mathrm{cm}$ indicam a possibilidade de entrada de esgoto no ambiente.

Os parâmetros de $\mathrm{pH}$ e turbidez apresentaram resultados no intervalo dos limites exigidos pelo Conselho Nacional do Meio Ambiente, conforme a Resolução 357/05, pH 6,0-9,0 e turbidez menor e igual a 100 NTU, na classificação de corpos d'água, classe 2. Peixoto $(2007)$ observou em estudos realizados na UHE Lajeado valores de $\mathrm{pH}$ na faixa de 7,6, variando de ligeiramente alcalino a neutro, o que segundo Vinatea-Arana (1997) pode ser considerado com a faixa de $\mathrm{pH}$ adequada para produção de pescado, variando de 6,5 a 9,0 e que valores de 4,0 e 11,0 (ácido e básico) são letais para a vida aquática.

Os valores de oxigênio dissolvido e sólidos totais dissolvidos (STD) em alguns pontos apresentaram resultados fora do limite da Resolução, conforme o enquadramento de classe 2: oxigênio dissolvido menor ou igual a $5 \mathrm{mgO}_{2} \mathrm{~L}^{-1} \mathrm{e}$ concentração máxima de STD de $0,0500 \mathrm{gL}^{1}$. O ponto $\mathrm{A} 5$ apresentou um valor de $4,250 \mathrm{mgO}_{2} \mathrm{~L}^{-1}$ e o ponto A2 com $0,0510 \mathrm{gL}^{1}$ de STD no decorrer do monitoramento. Embora um pouco acima dos parâmetros do CONAMA, estes parâmetros não sugerem indícios de alteração na qualidade da água. Peixoto (2007) e Marques (2006) em estudos na UHE Lajeado observaram valores diferentes de oxigênio dissolvido para a estação das chuvas, com concentração desse gás variando entre 6,30 mg/L e 11,66 $\mathrm{mg} / \mathrm{L}$ e de 6,74 mg/L e 8,60mg/L na época de seca. De acordo com Prado (1999), a concentração de oxigênio dissolvido em um corpo hídrico pode ser usada para a determinação da qualidade da água. Quanto mais reduzida for a concentração de oxigênio dissolvido, mais poluído o curso d'água se encontra, influenciando 
diretamente na biodiversidade aquática. Os valores abaixo $\left(4,25 \mathrm{mgO}_{2} \mathrm{~L}^{-1}\right)$ do limite tolerado da concentração de oxigênio dissolvido no reservatório de Lajeado podem estar relacionados ao consumo de oxigênio pela degradação da quantidade excessiva de matéria orgânica ou possuir forte influência dos processos pluviométricos. Já o excesso de sólidos na água, atribuído ao aumento da concentração dos sólidos totais dissolvidos, uma vez que nos períodos chuvosos há o escoamento de material superficial do solo para o reservatório pode afetar a comunidade aquática, alterando as condições de luminosidade e interferindo no metabolismo dos seres autotróficos (BUZELLI et al., 2013).

A concentração de clorofila-a nos pontos de amostragens coletados permaneceu dentro do valor tolerado pela Resolução do CONAMA 357/05, concentração de clorofila-a inferior a $30 \mu \mathrm{gCl}-\mathrm{aL}^{1}$, para corpo hídrico enquadrado na classe 2 (Tabela 1). O trabalho de Marques (2006) apontou médias próximas a $10,58 \mu \mathrm{gCl}-\mathrm{aL}^{1}$ no período das chuvas na UHE Lajeado, enquanto Reis Pereira (2002) observou concentrações de $12,78 \mu \mathrm{gCl}^{-\mathrm{aL}^{1}}$ na fase de enchimento do reservatório.

Os níveis médios de concentração de fósforo total encontrados durante o monitoramento apresentaram valores acima do permitido de acordo com a Resolução 357/05 (Tabela 1), para ambientes lênticos de água doce, classe 2 (0,030 $\left.\mathrm{mg} \mathrm{PL}{ }^{-1}\right)$. Neste caso, a concentração do fósforo pode ter sido influenciada tanto pela água pluvial como pela própria atividade da piscicultura, dificultando diferenciar o principal contribuinte de fósforo no sistema. O fósforo está diretamente ligado à produtividade da condição de um reservatório e tem sido apontado como o principal responsável pela eutrofização artificial (ESTEVES, 1998; BUZELLI et al., 2013). Peixoto (2007) calculou a concentração máxima de fósforo afluente admissível por ano para manter o ambiente do reservatório da UHE Lajeado mesotrófico e concluiu que haveria necessidade de reduzir a carga afluente de fósforo de $31.225 \mathrm{kgp}_{\text {.ano }}{ }^{-1}$ para 3.148 kgp.ano ${ }^{-1}$, ou seja, uma redução de 28,07 kgp.ano ${ }^{-1}$.

Na Tabela 1 são apresentados os valores utilizados para o cálculo do IET, Número de repetições (N), média e Desvio Padrão (Desv Pad) nas concentrações de Clorofila-a $\left(\mu \mathrm{gL}^{-1}\right)$ e fósforo total $\left(\mu \mathrm{gL}^{-1}\right)$ da área de estudo, entre os meses de janeiro a abril de 2017. 
Tabela 1. Número de repetições $(\mathrm{N})$, média e Desvio Padrão (Desv Pad) nas concentrações de Clorofila-a ( $\mu \mathrm{gL}-1)$, fósforo total ( $\mu \mathrm{gL}-1)$ e Ortofosfato ( $\mu \mathrm{gL}-1)$ da área de estudo, entre os meses de janeiro a abril de 2017

\begin{tabular}{|l|l|l|l}
\hline \multicolumn{1}{c|}{ Janeiro } & N & Média & Desv Pad \\
\hline Clorofila-a $\left(\mu \mathrm{gL}^{-1}\right)$ & & & \\
\hline Fósforo Total $\left(\mu \mathrm{gL}^{-1}\right)$ & 10 & 8,21 & 4,786 \\
\hline \multicolumn{1}{c|}{ Fevereiro } & 10 & 143,00 & 112,294 \\
\hline Clorofila-a $\left(\mu \mathrm{gL}^{-1}\right)$ & & & \\
\hline Fósforo Total $\left(\mu \mathrm{gL}^{-1}\right)$ & 10 & 6,14 & 1,494 \\
\hline \multicolumn{1}{c|}{ Março } & 10 & 57,25 & 4,779 \\
\hline Clorofila-a $\left(\mu \mathrm{gL}^{-1}\right)$ & & & \\
\hline Fósforo Total $\left(\mu \mathrm{gL}^{-1}\right)$ & 10 & 7,85 & 4,557 \\
\hline \multicolumn{1}{c|}{ Abril } & 10 & 100,00 & 37,844 \\
\hline Clorofila-a $\left(\mu \mathrm{gL}^{-1}\right)$ & & & \\
\hline Fósforo Total $\left(\mu \mathrm{gL}^{-1}\right)$ & 10 & 1,28 & 0,627 \\
\hline
\end{tabular}

A partir desses dados, foram calculados os Índices de Estado Trófico segundo Lamparelli (2004), considerando os parâmetros de clorofila-a e fósforo total. O Quadro 2 apresenta os resultados da média dos índices de estados tróficos de clorofila-a e fósforo total e o grau de trofia do ambiente a partir dos valores aproximados de todos os pontos de amostragens no período de janeiro a abril de 2017.

Quadro 2. Resultados da média dos índices de estados tróficos de clorofila-a e fósforo total e o grau de trofia do ambiente a partir dos valores aproximados de todos os pontos de amostragens no período de janeiro a abril de 2017

(Continua)

PONTO JANEIRO FEVEREIRO MARÇO ABRIL

\begin{tabular}{|l|l|l|l|l|l|}
\hline A1 & 64 & 64 & 65 & 56 & \\
\hline A2 & 65 & 62 & 66 & 49 & \\
\cline { 1 - 4 } A3 & 66 & 63 & 67 & 58 & \\
\hline A4 & 67 & 63 & 65 & 49 & \\
\hline A5 & 63 & 63 & 68 & 54 & Oligotraoligotrófico \\
\hline A6 & 62 & 64 & 63 & 53 & Mesotrófico \\
\hline
\end{tabular}


(Conclusão)

\begin{tabular}{c|c|c|c|c|l|}
\hline \multicolumn{1}{c}{ PONTO } & \multicolumn{1}{l}{ JANEIRO } & \multicolumn{1}{l}{ FEVEREIRO } & \multicolumn{1}{l}{ MARÇO } & \multicolumn{1}{l}{ ABRIL } \\
\hline A7 & 63 & 64 & 61 & 51 & Supereutrófico \\
\hline A8 & 69 & 64 & 68 & 53 & Hipereutrófico \\
\hline A9 & 73 & 62 & 65 & 36 & \\
A10 & 70 & 63 & 59 & 44 \\
Média & 66 & 63 & 65 & 50 \\
\hline
\end{tabular}

Com os índices calculados no Quadro 2, foram elaboradas imagens produzidas pelo software Quantum Gis 2.18, a partir da técnica de interpolação de pontos IDW (Inverse Distance Weighting). O Quadro 2 demonstra o perfil do grau de trofia durante os meses amostrados.

Em janeiro, quando houve índice de precipitação em torno de $250 \mathrm{~mm}$ de chuva (Gráfico 1), os pontos A4, A5, A9 e A8, localizados da área de criação de peixes, apresentaram índices hipereutróficos (> 67), e os pontos A1, A2, A3, A6 e A7 apresentaram índices entre supereutrófico (63-67) e eutrófico (59-63) com predominância de supereutrófico (Figura 3a). Em fevereiro, período que apresentou leve baixa no índice pluviométrico em torno de $200 \mathrm{~mm}$ (Gráfico 1), o índice do estado trófico predominante foi o supereutrófico com medidas pontuais de eutrófico nos pontos A2, A3, A4 e A9 (Figura 3b).

Em março, o índice pluviométrico foi em torno de $160 \mathrm{~mm}$ e o índice do estado trófico predominante na área foi o supereutrófico com medidas pontuais e hipereutrófico (A2 e A5) e eutrófico (A1, A6 e A7) (Figura 3c).

Em abril, período de menor índice pluviométrico observado no período (em torno de $80 \mathrm{~mm}$ ) o índice do estado trófico sofreu melhora, apresentando faixas entre mesotrófico (52-59) pontos A1, A2 e A5, oligotrófico (47-52) pontos A6, A7, A8 e A3 e ultraoligotrófico $(\leq 47)$ pontos A4 e A9, porém houve predominância de grau de trofia oligotrófico $(47<$ IET $\leq 52)$, sendo possível que este índice se confirme nos períodos de baixo índice pluviométrico; neste caso, a chuva parece possuir forte relação com o estado trófico do lago. 


\section{Índice de Estado Trófico - LAMPARELLI (2004)}
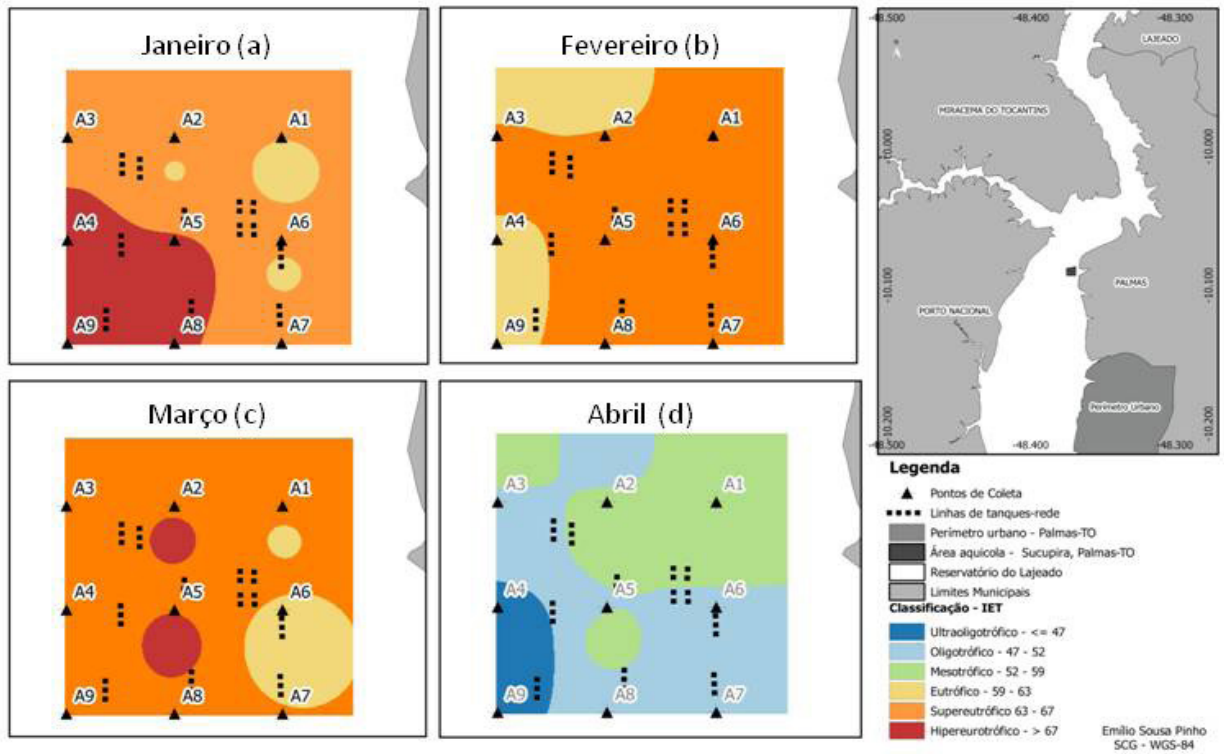

Figura 3. Perfil do estado trófico do polo aquícola localizado no município de Palmas (TO) entre os meses de janeiro e abril de 2017

Fonte: Lamparelli (2004).

O resultado do valor médio do índice de estado trófico de Lamparelli (2004) apresentou alto grau de trofia na região de produção de pescado sendo classificado como supereutrófico $(63<$ IET $\leq 67)$ na maioria dos pontos amostrados, durante os meses de janeiro, fevereiro e março. Devido ao período climático, não foi possível diferenciar o efeito sinérgico da chuva e da atividade da piscicultura sobre o estado trófico da área em estudo. Provavelmente, a interpretação dos índices de estado trófico ficará mais clara no período de estiagem, que ocorre a partir de maio a outubro, demandando mais estudos. Pena et al. (2004) realizaram campanhas de monitoramento em 16 pontos amostrais ao longo deste reservatório, durante os anos de 2002 e 2003, onde foram quantificados os parâmetros de transparência, clorofila-a e fósforo total. Os autores observaram que o reservatório da UHE Lajeado apresentou características mesotróficas a partir do cálculo de estado trófico pelo método de Toledo (1985), durante todo o período de estudo e sugeriram que as 
oscilações nos valores do cálculo de IET de transparência podem estar relacionadas à interferência de sólidos totais que implicam na condição do grau de trofia do ambiente.

\section{CONSIDERAÇÕES FINAIS}

Os dados obtidos permitem concluir que a área aquícola apresentou predominância de estado supereutrófico e que o estado trófico nas proximidades da área aquícola sofre forte influência do período de chuva, demandando estudos no período de menor índice pluviométrico.

As variáveis limnológicas, com exceção do fósforo total, apresentaram-se dentro dos padrões recomendados pela Resolução CONAMA 357/05, sendo que os resultados de oxigênio dissolvido e sólidos totais em alguns pontos amostrais apresentaram resultados pouco acima destes parâmetros, não sugerindo, porém, indícios de alteração na qualidade da água.

Os efeitos da atividade são difíceis de serem previstos a longo prazo, bem como o comportamento do reservatório mediante aumento de produção dos parques aquícolas, porém, caso não haja monitoramento e controle eficiente sobre a qualidade da água, a piscicultura em tanques-rede pode vir a promover degradação do ecossistema aquático.

\section{AGRADECIMENTO}

Os agradecimentos à Universidade Federal do Tocantins, através do seu Programa de Pós-Graduação em Ciências do Ambiente; à Faculdade Católica do Tocantins (Laboratório de Saneamento Ambiental); e ao Instituto de Educação Ciência e Tecnologia do Tocantins, Campus Palmas. 


\section{REFERÊNCIAS}

ALCÂNTARA, E.; CURTARELLI, M.; OGASHAWARA, I.; STECH, J.; SOUZA, A. Longterm environmental time series of continuously collected data in hydroelectric reservoirs in Brazil. Ambi-Agua, Taubaté, v. 8, n. 1, p. 6-17, 2013.

AMERICAN PUBLIC HEALTH ASSOCIATION. Standard methods for the examination of water and wastewater. 20. ed. Washington, 1998. p. 4-75/4-93.

BARBOSA, J. E. de L. et al. Diagnóstico do estado trófico e aspectos limnológicos de sistemas aquáticos da bacia hidrográfica do Rio Taperoá, trópico semi-árido brasileiro. Revista de Biologia e Ciências da Terra, v. 12, n. 1, p. 81, 2006.

BRASIL. Conselho Nacional de Meio Ambiente. Resolução no 357, de 17 de março de 2005. Dispõe sobre a classificação dos corpos de água e diretrizes ambientais para o seu enquadramento, bem como estabelece as condições e padrões de lançamento de efluentes, e dá outras providências. Disponível em: http://pnqa.ana. gov.br/Publicacao/RESOLUCAO_CONAMA_n_357.pdf. Acesso em: 28 set. 2016.

BRASIL. Lei no 9433/1997, de 08 de janeiro de 1997. Institui a Política Nacional de Recursos Hídricos, cria o Sistema Nacional de Gerenciamento de Recursos Hídricos, regulamenta o inciso XIX do art. 21 da Constituição Federal, e altera 0 art. $1^{\circ}$ da Lei $n^{\circ} 8.001$, de 13 de março de 1990, que modificou a Lei $n^{0} 7.990$, de 28 de dezembro de 1989. Diário Oficial da União Federativa do Brasil - DOU, Brasília, 9 de janeiro de 1997.

BUZELLI, G. M.; CUNHA-SANTINO, M. B. Análise e diagnóstico da qualidade da água e estado trófico do reservatório de Barra Bonita (SP). Ambi-Agua, Taubaté, v. 8, n. 1, p. 186-205, 2013. DOI: http://dx.doi.org/10.4136/ambi-agua.930.

CARLSON, R. E. A trophic state index for lakes. Limnolog y and Oceanography, v. 22, p. 361-369, 1977.

COMPANHIA AMBIENTAL DO ESTADO DE SÃO PAULO. Relatório de qualidade das águas interiores do estado de São Paulo 2008. São Paulo: CETESB, 2009a. p. 531. (Série Relatórios da Secretaria de Estado do Meio Ambiente, v. 1). 
COMPANHIA AMBIENTAL DO ESTADO DE SÃO PAULO. Variáveis de qualidade de água. São Paulo: CETESB, 2009b. Disponível em: http://www.cetesb.sp.gov.br/ Agua/rios/variaveis.asp\#transparencia. Acesso em: 20 out. 2016.

DEUS, R. et al. Impact evaluation of a pisciculture in the Tucuruí reservoir (Pará, Brazil) using a two-dimensional water quality model. Journal of Hydrolog y, v. 487, p. 1-12, 2013. DOI: http://dx.doi.org/10.1016/j.jhydrol.2013.01.022.

ESTEVES, F. de A. Fundamentos em limnologia. 2. ed. Rio de Janeiro: Interciência/FINEP, 1998.

FOOD AND AGRICULTURE ORGANIZATION. The state of world fisheries and aquaculture 2016. Contributing to food security and nutrition for all. Roma: FAO, 2016. 200 p.

KUBITZA, F. Qualidade da água no cultivo de peixes e camarões. Jundiaí: Editora Degaspari, 2003. 229 p.

LAMPARELLI, M. C. Grau de trofia em corpos d'água do Estado de São Paulo: avaliação dos métodos de monitoramento. 2004. 207 f. Tese (Doutorado) - Universidade de São Paulo, São Paulo, 2004.

MALLASEN, Margarete et al. Qualidade da água em sistema de piscicultura em tanques-rede no reservatório de Ilha Solteira, SP. Boletim do Instituto de Pesca, São Paulo, v. 38, n. 1, p. 15-30, 2012.

MARQUES, A. K. Análise da diversidade fitoplanctônica no reservatório da Usina Hidroelétrica Luis Eduardo Magalhães, no médio Tocantins - TO: estrutura da comunidade, flutuações temporais e espaciais. 2006. 158 f. Dissertação (Mestrado em Ciências do Ambiente) - Universidade Federal do Tocantins, Palmas, 2006.

MURPHY, J.; RILEY, J. P. A Modified single solution method for the determination of phosphate in natural water. Analytica Chimica Acta, v. 27, p. 31-36, 1962.

ORGANIZATION FOR ECONOMIC COOPERATION AND DEVELOPMENT. Eutrophication of water: monitoring, assessment and control. Paris: OECD, 1982. 154 p. 
PADUA, H. B. Principais variáveis físicas e químicas da água na aqüicultura. In: WORKSHOP QUALIDADE DE ÁGUA NA AQÜICULTURA, 1996, São Paulo. Anais [...]. São Paulo: CEPTA/IBAMA, 1996. p. 1-58.

PEIXOTO, R. H. P. B. Efeitos da implantação do reservatório da Usina Hidrelétrica Luis Eduardo Magalhães sobre a qualidade da água do rio Tocantins (TO, Brasil). 2007. 222 f. Tese (Doutorado) - Instituto de Geociências, Universidade Federal do Rio de Janeiro, Rio de Janeiro, 2007.

PENA, L.; FERREIRA, C.; ALMEIDA, M. Comportamento dos índices do estado trófico de Carlson (IET) e modificado (IETM) no reservatório da UHE Luís Eduardo Magalhaes. Tocantins-Brasil. In: CONGRESO INTERAMERICANO DE INGENIERÍA SANITARIA Y AMBIENTAL, 29., 2004. Anais [...]. San Juan: AIDIS, 2004. p. 6.

PEZZATO, L. E. et al. Nutrição de peixes. In: CYRINO, J. E. P. et al. Tópicos especiais em piscicultura de água doce tropical intensiva. São Paulo: TecArt, 2004. p. $75-170$.

PRADO, R. B. Influência do uso e ocupação do solo na qualidade da água: estudo no médio rio Pardo - SP (período de 1985 a 1997). 1999. 209 f. Dissertação (Mestrado em Ciências da Engenharia Ambiental) - Escola de Engenharia de São Carlos, Universidade de São Paulo, São Carlos, 1999.

SALAS, H. J.; MARTINO, P. A simplified phosphorus trophic state model for warm-water tropical lakes. Water Research, v. 25, n. 3, p. 1341-350, 1991.

SMITH, V. H.; SCHINDLER, D. W. Eutrophication science: where do we go from here? Trends in Ecology and Evolution, n. 24, p. 201-207, 2009.

TOLEDO JÚNIOR, A. P. Informe preliminar sobre os estudos para a obtenção de um índice para avaliação do estado trófico de reservatórios de regiões quentes tropicais. São Paulo: CETESB, 1990. 12 p.

TUNDISI, J. E. M. Indicadores da qualidade da bacia hidrográfica para gestão integrada dos recursos hídricos: estudo de caso: Bacia hidrográfica do Médio Tocantins (TO). 2006. 153 f. Tese (Doutorado em Ciências Biológicas) - Universidade 
Federal de São Carlos, São Carlos, 2006.

TUNDISI, J. G.; MATSUMURA-TUNDISI, T. Limnologia. São Paulo: Oficina de Textos, $2008.631 \mathrm{p}$.

VALENTI, W. C.; PEREIRA, J. A.; BORGHETTI, J. R. Aquicultura no Brasil: bases para um desenvolvimento sustentável. Brasília: CNPq, 2000. 399 p.

VINATEA-ARANA, L. Princípios químicos de qualidade da água em aqüicultura. Florianópolis: Editora da UFSC, 1997. 166 p.

VOLLENWEIDER, R. A. Scientific fundamentals of the eutrophication of lakes and flowing waters with particular reference to nitrogen and phosphorus as factors in eutrophication. Paris: OECD, 1968. 192 p.

WETZEL, R. G. Limnologia. Lisboa: Fundação Calouste Gulbenkian, 1993. 919 p.

Recebido em: 12/01/2018

Aceito em: 17/07/2018 